\title{
EXPERIMENTAL STUDY OF DOUBLE POINT CUTTING TOOL ON CHIP - TOOL INTERFACE TEMPERATURE IN TURNING
}

\author{
S.Vanangamudi ${ }^{1}$, M.Pradeep Kumar ${ }^{2}$ \\ ${ }^{1}$ Research Scholar, Department of Mechanical Engineering, Bharath Institute of Higher Education and Research, \\ Chennai - 600 073, India. \\ Email:vanangamudi_s@yahoo.com \\ ${ }^{2}$ Associate Professor, Department of Mechanical Engineering, College of Engineering, Anna University, \\ Chennai-600 025, India
}

\begin{abstract}
A special type of a tool is designed and made to have two cutting points for turning long workpieces and it may be termed as the double point cutting tool. The double point cutting tool has two cutting points which has the height difference of 0.5 mm and the distance between them is $6 \mathrm{~mm}$. So that when the first cutting point takes $0.5 \mathrm{~mm}$ depth of cut and next to that the second cutting point also takes $0.5 \mathrm{~mm}$ depth of cut as the tool proceeds for turning. Hence the total machining time is reduced considerably. Chip - Tool Interface Temperature takes very important role in metal cutting which decides the dimensional accuracy, mechanical properties of the workpiece and the tool life. Investigation on Chip - Tool Interface Temperature in HSS Double Point Cutting Tool during turning of Mild Steel for different cutting conditions is presented in this Research article.
\end{abstract}

Keywords: double point cutting tool, machining time, chip - tool interface temperature, dimensional accuracy, mechanical properties of the work piece, tool life

\section{INTRODUCTION}

A special type of a tool is designed and made to have two cutting points for turning long workpieces and it may be termed as the double point cutting tool. The double point cutting tool has two cutting points which has the height difference of $0.5 \mathrm{~mm}$ and the distance between them is 6 $\mathrm{mm}$. So that when the first cutting point takes $0.5 \mathrm{~mm}$ depth of cut and next to that the second cutting point also takes 0.5 $\mathrm{mm}$ depth of cut as the tool proceeds for turning. Hence the total machining time is reduced considerably. Chip - Tool Interface Temperature takes very important role in metal cutting which decides the dimensional accuracy, mechanical properties of the workpiece and the tool life.

Special feature of the double point cutting tool over single point cutting is that the total machining time is reduced considerably. For reducing the diameter from $50 \mathrm{~mm}$ to 40 $\mathrm{mm}$ for the length $200 \mathrm{~mm}$, the double point cutting tool takes only half of the time taken by the single point cutting tool when the depth of cut is $0.5 \mathrm{~mm}$ for different speed and feed conditions.

\section{EXPERIMENTAL SETUP}

Mild Steel Rod of $50 \mathrm{~mm}$ diameter and $300 \mathrm{~mm}$ long is used as Workpiece for turning. HSS Double Point Cutting tool which has two cutting points of the height difference of 0.5 $\mathrm{mm}$ and the distance between them is $6 \mathrm{~mm}$ is used as Cutting tool for turning. The purchased HSS tool bit has been ground to the required tool geometry by using Tool and Cutter grinding machine. Infrared Pyrometer has been used to measure the tool-chip interface temperature. A minimum temperature of $90.4^{0} \mathrm{C}$ and a maximum temperature of $154.3^{0} \mathrm{C}$ are recorded around the cutting Zone. Nine experiments have been conducted on the precision Centre Lathe by keeping the depth of cut $0.5 \mathrm{~mm}$ as constant for various feed and speed for measuring the temperature.

The double point cutting tool is fixed in the tool post by referring the dead centre of the tailstock and accordingly adjustment is made by keeping metal strips under the tool so that the cutting points coincide with the axis of the center i.e., axis of the workpiece. The MS workpiece of $50 \mathrm{~mm}$ diameter and $300 \mathrm{~mm}$ long is fixed in the three jaw chuck and the other end of the workpiece is supported by the tailstock.

\section{EXPERIMENTATION}

Figure: 1 shows that the double point tool is ready for turning. The depth of cut $05 \mathrm{~mm}$ is taken as constant value for the $1^{\text {ST }}$ set of speed and different feed rate such as 135 $\mathrm{rpm}, 0.205 \mathrm{~mm} / \mathrm{rev}, 0.238 \mathrm{~mm} / \mathrm{rev}$ and $0.260 \mathrm{~mm} / \mathrm{rev}$ and $2^{\text {nd }}$ set of speed and different feed rate such as $215 \mathrm{rpm}$ $0.205 \mathrm{~mm} / \mathrm{rev}, 0.238 \mathrm{~mm} / \mathrm{rev}$ and $0.260 \mathrm{~mm} / \mathrm{rev}$ and $3^{\text {rd }}$ set of speed and different feed rate such as $325 \mathrm{rpm} 0.205$ $\mathrm{mm} / \mathrm{rev}, 0.238 \mathrm{~mm} / \mathrm{rev}$ and $0.260 \mathrm{~mm} / \mathrm{rev}$ respectively. 


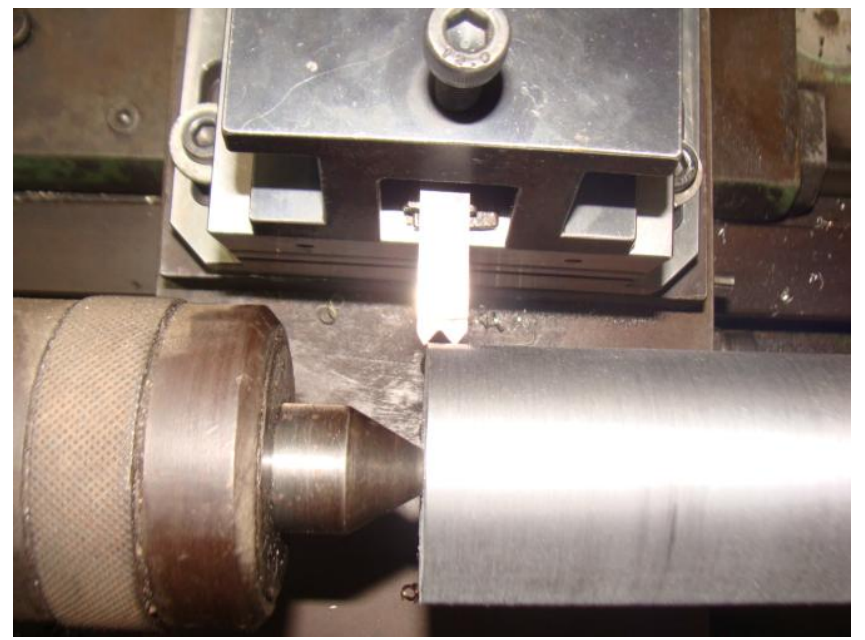

Figure: 1 Double Point Cutting Tool for Turning

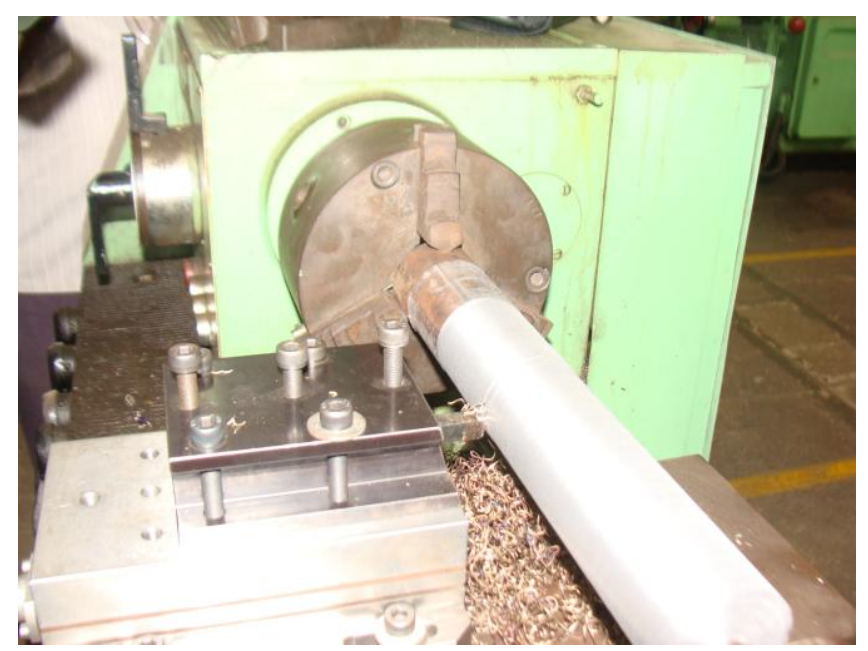

Figure: 2 Double Point Cutting Tool does Turning

During the turning operation the infrared pyrometer is used for measuring the chip-tool interface temperature by placing the same precisely $400 \mathrm{~mm}$ above the chip-tool interface. Readings are recorded for the different speed and feed by keeping the depth of cut $0.5 \mathrm{~mm}$ as constant. So totally nine experiments have been conducted and recorded.

\section{RESULTS AND DISCUSSION}

The depth of cut $0.5 \mathrm{~mm}$ is kept constant for all the nine experiments.

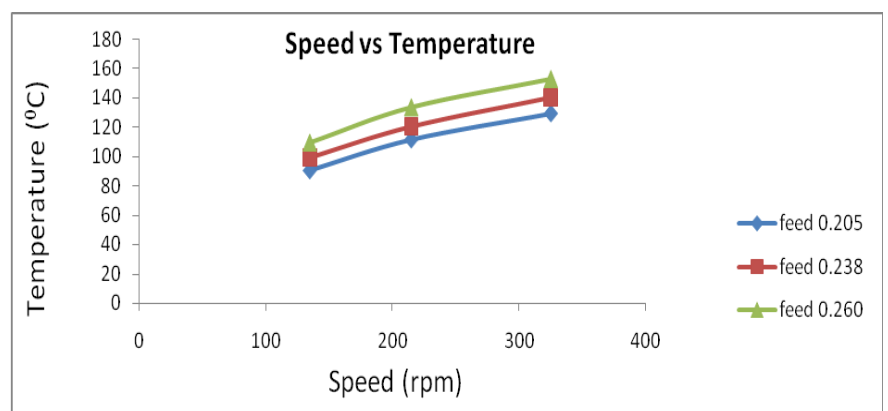

Figure: 3 Double Point Cutting Tool: First Point: Speed (rpm) Vs Temperature $\left({ }^{0} \mathrm{C}\right)$

\section{I.Speed (N):}

Case (i )

For the feed $0.205 \mathrm{~mm} / \mathrm{rev}$ and the speed $135 \mathrm{rpm}$ the chiptool interface temperature is recorded as $90.4^{0} \mathrm{C}$. When the speed is increased to $325 \mathrm{rpm}$, the chip-tool interface temperature is increased and recorded as $129.6^{\circ}$ C. I.e., the chip-tool interface temperature is increased by 1.43 times.

Case (ii)

For the feed $0.238 \mathrm{~mm} / \mathrm{rev}$ and the speed $135 \mathrm{rpm}$ the chiptool interface temperature is recorded as $99.5^{\circ} \mathrm{C}$. When the speed is increased to 325 , the chip-tool interface temperature is increased and recorded as $140.2^{0} \mathrm{C}$. I.e., the chip-tool interface temperature is increased by 1.40 times.

Case (iii)

For the feed $0.260 \mathrm{~mm} / \mathrm{rev}$ and speed $135 \mathrm{rpm}$ the chip-tool interface temperature is recorded as $109.7^{\circ} \mathrm{C}$. When the speed is increased to $325 \mathrm{rpm}$, the chip-tool interface temperature is increased and recorded as $152.7^{\circ} \mathrm{C}$. I.e ., the chip-tool interface temperature is increased by 1.39 times.

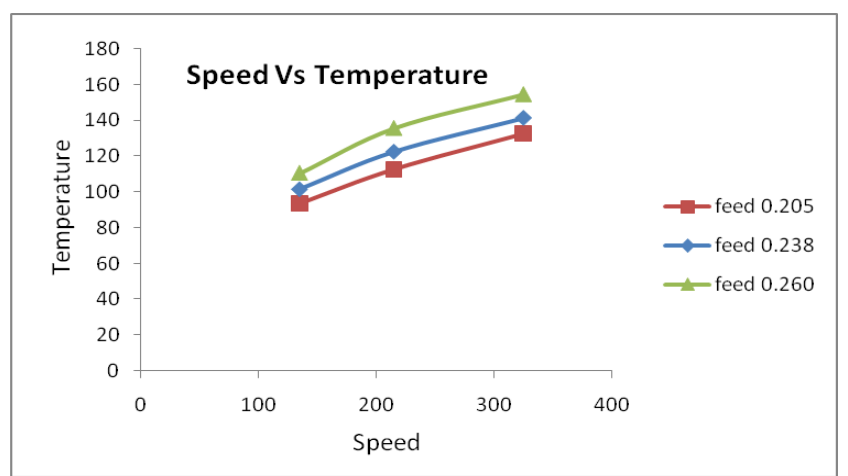

Figure : 4 Double Point Cutting Tool : Second Point : Speed (rpm) Vs Temperature $\left({ }^{0} \mathrm{C}\right)$

Same trend is noticed even for the second point of the double point cutting tool. Figure: 4 shows the same.

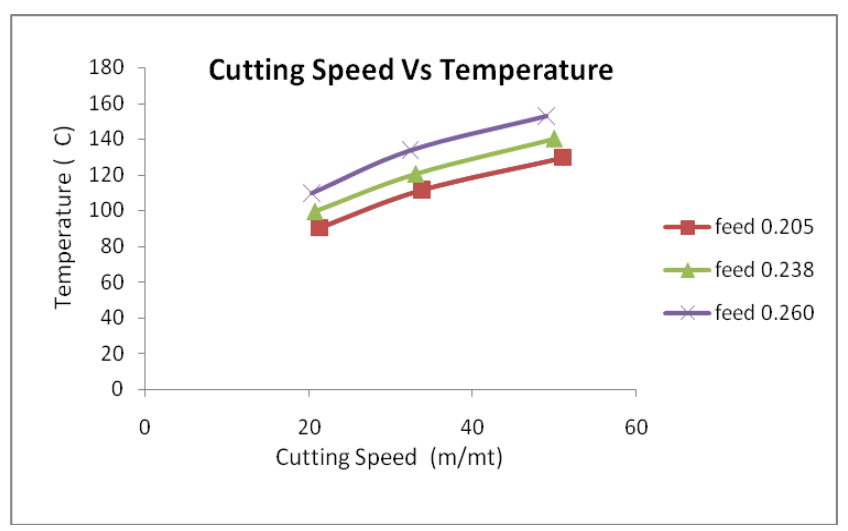

Figure: 5 Double Point cutting tool: First Point: Cutting speed vs Temperature

\section{Cutting Speed (V):}

The value of the cutting speed (V) depends on the diameter of the workpiece to be turned and speed of rotation of the 
workpiece $(\mathrm{N})$ and they influence the chip-tool interface temperature.

\section{Case (i )}

For the feed $0.205 \mathrm{~mm} / \mathrm{rev}$ and the cutting speed 21.195 $\mathrm{m} / \mathrm{mt}$ the chip-tool interface temperature is recorded as $90.4^{0}$ C. When the cutting speed is increased to $51.025 \mathrm{~m} / \mathrm{mt}$, the chip-tool interface temperature is increased and recorded as $129.6^{0}$ C. I.e., the chip-tool interface temperature is increased by 1.43 times.

\section{Case(ii )}

For the feed $0.238 \mathrm{~mm} / \mathrm{rev}$ and the cutting speed 20.771 $\mathrm{m} / \mathrm{mt}$ the chip-tool interface temperature is recorded as $99.5^{0}$ C. When the cutting speed is increased to $50.005 \mathrm{~m} / \mathrm{mt}$, the chip-tool interface temperature is increased and recorded as $140.2^{0}$ C. I.e., the chip-tool interface temperature is increased by 1.40 times.

\section{Case ( iii )}

For the feed $0.260 \mathrm{~mm} / \mathrm{rev}$ and the cutting speed 20.347 $\mathrm{m} / \mathrm{mt}$ the chip-tool interface temperature is recorded as $109.7^{0} \mathrm{C}$. When the cutting speed is increased to 48.984 $\mathrm{m} / \mathrm{mt}$, the chip-tool interface temperature is increased and recorded as $152.7^{0}$ C. I.e., the chip-tool interface temperature is increased by 1.39 times.

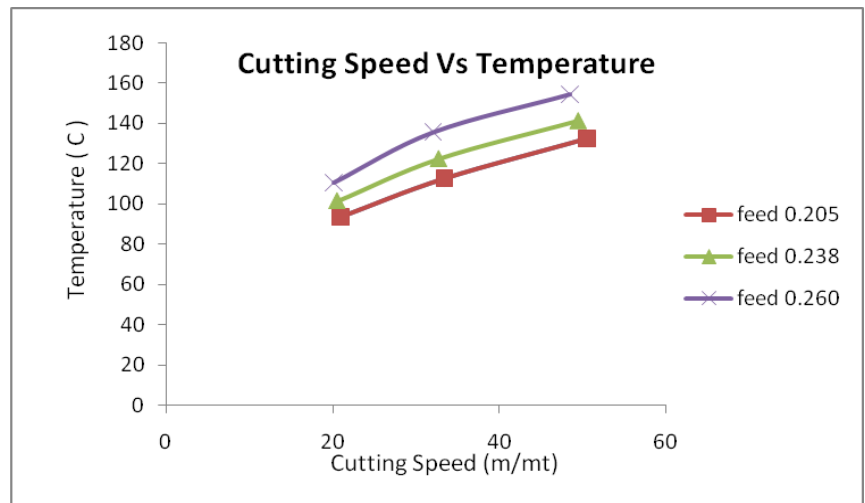

Figure: 6 Double Point cutting tool: Second Point: Cutting speed vs Temperature

Same trend is noticed even for the second point of the double point cutting tool. Figure : 7 shows the same.

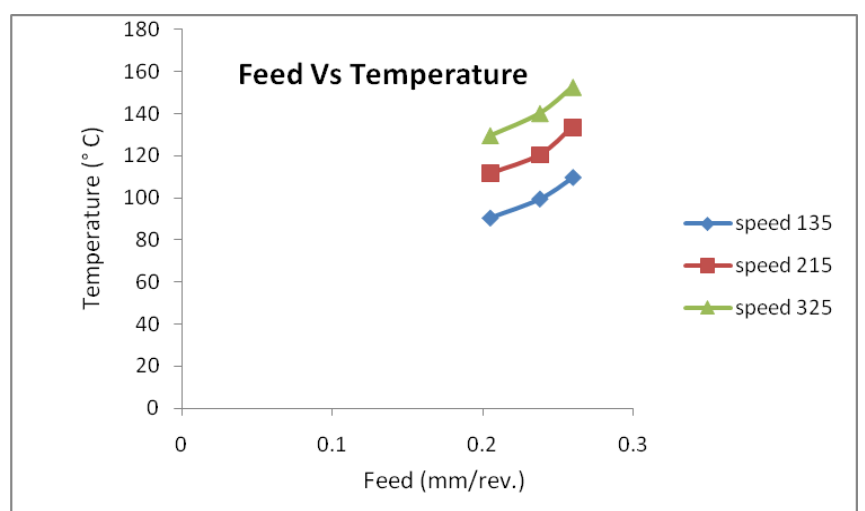

Figure: 7 Double Point cutting tool: First Point: Feed vs Temperature
III. Feed (f)

Case (i )

For the speed $135 \mathrm{rpm}$ and the feed $0.205 \mathrm{~mm} / \mathrm{rev}$ the chiptool interface temperature is recorded as $90.4^{0} \mathrm{C}$. When the feed is increased to $0.260 \mathrm{~mm} / \mathrm{rev}$, the chip-tool interface temperature is increased and recorded as $109.7^{\circ} \mathrm{C}$. I.e., the chip-tool interface temperature is increased by 1.21 times.

Case (ii )

For the speed $215 \mathrm{rpm}$ and the feed $0.205 \mathrm{~mm} / \mathrm{rev}$ the chiptool interface temperature is recorded as $111.6^{\circ} \mathrm{C}$. When the feed is increased to $0.260 \mathrm{~mm} / \mathrm{rev}$, the chip-tool interface temperature is increased and recorded as $133.6^{\circ} \mathrm{C}$. I.e, the chip-tool interface temperature is increased by 1.20 times.

Case (iii)

For the speed $325 \mathrm{rpm}$ and the feed $0.205 \mathrm{~mm} / \mathrm{rev}$ the chiptool interface temperature is recorded as $129.6^{\circ} \mathrm{C}$. When the feed is increased to $0.260 \mathrm{~mm} / \mathrm{rev}$, the chip-tool interface temperature is increased and recorded as $152.7^{\circ} \mathrm{C}$. I.e., the chip-tool interface temperature is increased by 1.18 times.

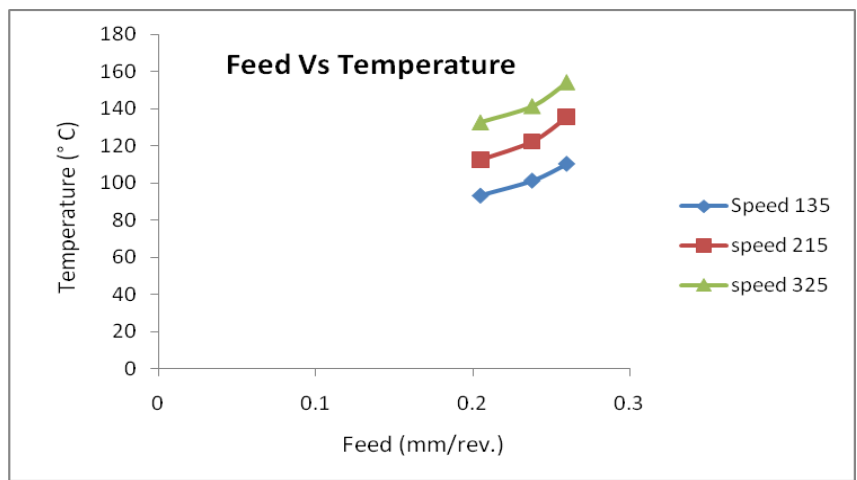

Figure : 8 Double Point cutting tool : Second Point : Feed vs Temperature

Same trend is noticed even for the second point of the double point cutting tool. Figure: 8 shows the same.

Lowen and Shaw ${ }^{[1]}$ stated that the cutting temperature is the function of cutting speed and feed rate. Yes! It is true even with respect to the double point cutting tool. The experiment results of double point cutting tool on chip-tool interface temperature well correlated with the cutting speed and feed rate. As the cutting speed and feed rate increase, the chiptool interface temperature also increases accordingly. On comparing all the cases it is very clear that the speed and cutting speed have greater effect on the chip-tool interface temperature than the feed rate.

\section{CONCLUSION:}

Single point cutting tool does single work! Double point cutting tool does double work !! There is famous proverb that is "Do or Die ". My tool says "Do and Alive "!!!. The performance of the double point cutting tool is quite satisfactory. The investigation on chip-tool interface temperature in HSS double point cutting tool obeys with 
HSS single point cutting tool . That is as the cutting speed increases the chip-tool interface temperature also increases and the feed rate has little effect in the chip tool interface temperature.

\section{REFERENCES}

[1] Lowen E.G., Shaw M.C. on the analysis of cutting tool temperatures Trans.ASME.1954: 76:217-231

[2] Abhang L.B.,Hameedullah M. The measurement of toolchip interface temperature in the turning of Steel. Int.J.Comput.Commun.Inf.Syst. (IJCCIS) 2010; 2: 1-5

[3] Fata A. Temperature measurement during machining depending on cutting conditions P\&A Sci. Technol. 2011; 1: 16-21

[4] Casto, S.Lo. Valvo,E.Lo., Micari, F., 1986 . Measurement of Temperature distribution within tool in metal cutting. Experimental test and numerical analysis. Journal of mechanical working technology 20, 35-46

[5] Chinchanikar, S., Choudhury S.K and Kulkarni, A.P., 2013 Investigation of chip-tool temperature during turning of hardened AISI 4340 alloy steel using multi-layer coated carbide inserts. Advanced Materials Research 701,354-358.

[6] X.J.Ren,Q.X.Yang,R.D. James, L. Wang, 2004, Cutting temperatures in hard turning chromium hardfacing with PCBN tooling “ Journal of Materials Processing Technology 147, 38-44

[7] Abhijeet Amritkar, Chandra Prakash, Atul Kulkarni, 2012 "Development of temperature measurement setup for machining "World journal of science and technology 2, 1519.

[8] Asmaa A. Kawi. Temperature behavior of some alloy steels in turning process under different operating conditions., Al-Qadisiya Journal for Engineering Sciences , 2011 Vol4 No 3

[9] Ram Chandra Kisku. Modelling of Temperature profile in turning with uncoated and coated cemented carbide insert, National Institute of Technology, 2011, 1-37

[10] Onyechi Pius, Oluwadare, Benjamin S., Obuka Nnaemeka , 2013, “ Analytical Modeling of Temperature Distribution in Metal Cutting : Finite element approach" International Journal of Engineering Science Invention, 1733

[11] Sullivan O., Cotterm M. Temperature measurement in single point turning. J . Mater. Process. Technol. 2001; 118: 301-318 